\title{
Preoperative platelet to Iymphocyte and neutrophil to lymphocyte ratios are independent prognostic factors for patients undergoing lung cancer radical surgery: A single institutional cohort study
}

\author{
Haidan Lan ${ }^{1, *}$, Leng Zhou ${ }^{1, *}$, Dongmei Chi ${ }^{1}$, Qinghua Zhou ${ }^{2}$, XiaoJun Tang ${ }^{2}$, Daxing \\ Zhu' ${ }^{2}$, Jianmin Yue ${ }^{1}$ and Bin Liu ${ }^{1}$ \\ ${ }^{1}$ Department of Anesthesiology, West China Hospital of Sichuan University, Chengdu, Sichuan, China \\ ${ }^{2}$ The lung cancer center, West China Hospital of Sichuan University, Chengdu, Sichuan, China \\ * These authors have contributed equally to this work \\ Correspondence to: Bin Liv, email: liubinhxyy@163.com \\ Keywords: non small cell lung cancer; platelet to lymphocyte ratio; neutrophil to lymphocyte ratio; postoperative pulmonary \\ complications; overall survival \\ Received: September 02,2016 Accepted: October 28, $2016 \quad$ Published: November 11, 2016 \\ Copyright: Lan et al. This is an open-access article distributed under the terms of the Creative Commons Attribution License (CC-BY), which \\ permits unrestricted use, distribution, and reproduction in any medium, provided the original author and source are credited.
}

\section{ABSTRACT}

Background: The aim of this study was to assess the prognostic value for NSCLC patients who were scheduled to receive lung cancer radical resection.

Methods: In this cohort study (Dec.2014-Feb.2016), patients with non-small cell lung cancer (NSCLC) who underwent radical lung cancer thoracotomy were enrolled and accessed at postoperative complications, one-year overall survival (OS) and relapse-free survival (RFS). The preoperative PLR and NLR of all patients were calculated based on preoperative complete blood counts. Univariate and multivariate Cox regression analyses were performed to determine the associations of PLR and NLR with OS and RFS.

Results. A total of 174 NSCLC patients were studied. The results indicated that both high PLR (>148.6) and NLR (>2.9) were related to a high rate of postoperative pulmonary complications significantly (49.3\%vs.29.1\%, $P=0.007 ; 50.7 \%$ vs. $28.6 \%$, $P=0.003)$. Moreover, NSCLC patients with a high PLR level $(>148.6)$ was significantly associated with a lower one-year OS $(90.3 \%$ vs. $77.5 \%, P=0.034)$.

Conclusions. Preoperative PLR and NLR were good prognostic factors for postoperative pulmonary complications and OS in NSCLC patients undergoing radical lung cancer surgery. Thus, blood PLR and NLR would be helpful as a prognostic tool before radical lung cancer surgery.

\section{INTRODUCTION}

Lung cancer is the most common malignancy, and it is also the leading cause of cancer death worldwide [1]. The primary treatment measure for lung cancer is radical lung cancer surgery $[2,3]$. Although great advance in lung cancer surgery has developed, the prognosis of lung cancer is still unsatisfactory. Studies reported that the median survival time for lung cancer in China is only 22.7 months [2]. Until now, ideal method to evaluate the prognosis of lung cancer remains unavailable. Thus, it is urgent and essential to identify a reliable prognostic marker for patients who were scheduled to receive lung cancer surgery. It would help clinicians to make good risk stratification and choose individualized therapy strategies for lung cancer patients.

In lung cancer radical thoracotomy, the preoperative immune status has a close relationship with clinical outcomes according to recent studies $[4,5]$. Besides, accumulating evidence has shown that the development 
and progression of tumor were associated with systemic inflammation because a cross-talk between inflammation and cancer might occur during perioperative period $[6$, 7]. As the conceptual tumor develops over last decade, evading immune destruction has become a cancer progress hallmark [6]. Systemic inflammatory response plays an important role in cancer development or progression but different inflammation-based indices account for different type of cancer $[8,9]$. Theoretically, inflammatory status should convey valuable information of lung cancer development or progression but unfortunately most specific inflammatory factors are not accessible before surgery and some are only available as research tools.

Preoperative platelet to lymphocyte ratio (PLR) and neutrophil to lymphocyte ratio (NLR) are two simply and widely available markers to reflect systemic inflammation status [10]. These two markers have been shown to be prognostic for several cancer types such as gastric, colorectal, liver and pancreatic cancers [9, 11-13]. Increased circulating platelets may contribute to tumor cell emboli and finally accelerate the course of tumor progression. Surgery promotes the formation of platelet clots around tumor cell emboli, thereby impairing NK cell-mediated tumor cell clearance, whereas perioperative anticoagulation attenuates this effect [14]. Preoperative high NLR relate to increased neutrophil-dependent inflammation, and reduced lymphocyte-mediated tumor response. Neutrophils may be recruited to lung carcinomas to enhance the invasive and metastatic potential of lung cancer cells [15]. An excess of neutrophil elastase is significantly associated with lung cancer risk [16].
Moreover, neutrophils can favor tumor development and inhibit the activity of lymphocytes and other immune cells. All the factors mentioned above is closely related to prognosis of lung cancer radical surgery. However, few prospective studies have investigated the association between preoperative PLR or NLR level and NSCLC clinical outcomes including postoperative pulmonary complications and one-year overall survival. Therefore, we conducted a prospective observational study to investigate the relationship between PLR or NLR and early clinical outcomes or one-year survival in NSCLC patients after lung cancer radical surgery.

\section{RESULTS}

\section{Patient characteristics}

The demographic and clinical characteristics of study population are summarized in Table 1. Between December 2014 and February 2016, a total of 435 patients were screened of whom 186 were enrolled finally and 174 (95.38\%) were confirmed with NSCLC based on postoperative pathology. The mean age of the 174 patients was 59.02 years (SD 11.33) with 122 (70.1\%) male patients. The most common initial clinical symptom was cough and expectoration (43.1\%). Almost a quarter of patients were found lung cancer through health examination without any clinical symptom. Only 20 percent people had adjuvant therapy before surgery.

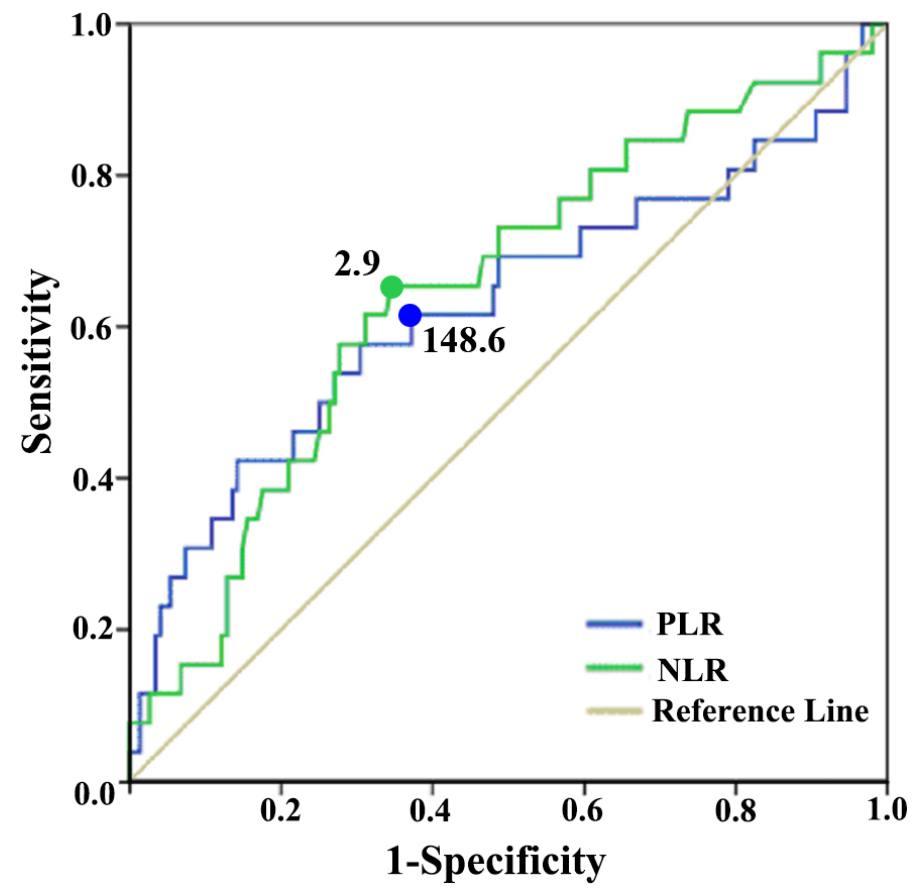

Figure 1: ROC curves for survival predication. ROC curves were potted to verify the accuracy of PLR and NLR for survival. The area under the curve (AUC) was $0.628(P=0.037,0.493-0.763)$ for PLR, and $0.648(P=0.016,0.531-0.766)$ for NLR. 
Table 1: Demographic and clinical characteristics of study population

\begin{tabular}{|l|l|}
\hline Characteristics & Value \\
\hline Subjects & 174 \\
\hline Age, years & $59.02 \pm 11.33$ \\
\hline Gender & \\
\hline Male & $122(70.1 \%)$ \\
\hline Female & $52(29.9 \%)$ \\
\hline Body-mass index, $\mathrm{kg} / \mathrm{m}^{2}$ & $23.1 \pm 2.90$ \\
\hline Smoking history & \\
\hline Never & $64(36.8 \%)$ \\
\hline Smoker & $110(63.2 \%)$ \\
\hline ASA classification & \\
\hline I & $11(6.3 \%)$ \\
\hline II & $125(71.8 \%)$ \\
\hline III & $38(21.8 \%)$ \\
\hline Lung function & \\
\hline FVC $(\mathrm{L})$ & $3.07 \pm 0.80$ \\
\hline FEV1 $(\mathrm{L})$ & $2.30 \pm 0.64$ \\
\hline FEV1/FVC $(\%)$ & $74.10 \pm 10.80$ \\
\hline Comorbidities & \\
\hline Hypertension & $28(16.1 \%)$ \\
\hline Diabetes mellitus & $14(8.1 \%)$ \\
\hline Heart disease & $25(14.4 \%)$ \\
\hline COPD & $35(20.1 \%)$ \\
\hline Clinical symptoms & \\
\hline No & $40(23.0 \%)$ \\
\hline Cough or expectoration, & $75(43.1 \%)$ \\
\hline Haemoptysis & $28(16.1 \%)$ \\
\hline Chest pain & $19(10.9 \%)$ \\
\hline Others & $12(6.9 \%)$ \\
\hline Adjuvant therapy & $35(20.1 \%)$ \\
\hline AFP $(\mathrm{ng} / \mathrm{mL})$ & $6.50 \pm 30.98$ \\
\hline CEA $(\mathrm{ng} / \mathrm{mL})$ & $20.03 \pm 66.87$ \\
\hline CA199 $(\mathrm{U} / \mathrm{mL})$ & $20.78 \pm 32.33$ \\
\hline CA125 (U/mL) & $117.92 \pm 824.68$ \\
\hline PLR & $157.11 \pm 87.95$ \\
\hline NLR & $2.82 \pm 1.58$ \\
\hline Dar & \\
\hline
\end{tabular}

Data are presented as $\mathrm{n}(\%)$ or mean \pm standard differences (SD).

COPD: chronic obstructive pulmonary disease; ASA: American society of anesthesiologists;

FEV1: forced expiratory volume in one second; AFP: alpha fetal protein; CEA: carcino embryonie antigen; PLR: platelet to lymphocyte ratio; NLR: neutrophil to lymphocyte ratio.

\section{Association between the PLR or NLR and clinicopathological characteristics}

The association between preoperative PLR or NLR and clinicopathological characteristics is shown in Table 2. The patients' preoperative PLR values distributed evenly among clinicopathological parameters, except for pathological type. Patients with squamous cell cancer have a higher PLR than adenocarcinoma $(P=0.006$, Table 2$)$. The preoperative NLR was significantly higher in patients with the following characteristics: male $(P=0.001)$, haemoptysis $(P=0.014)$, smoker $(P=0.010)$, squamous carcinoma $(P=0.012)$ (Table 2$)$.

\section{Receiver operating characteristic curve of PLR and NLR for OS prediction}

The optimal cutoff values for PLR and NLR to predict OS were identified by the receiver operating characteristic (ROC) curve (Figure 1). They were 148.6 
Table 2: The relationship between PLR, NLR and clinicopathological characteristics

\begin{tabular}{|c|c|c|c|c|c|}
\hline & $N=174$ & PLR & $P$ value & NLR & $P$ value \\
\hline \multicolumn{6}{|l|}{ Age, year } \\
\hline$\leq 60$ & $88(50.6 \%)$ & $155.55 \pm 70.62$ & 0.557 & $2.77 \pm 1.46$ & 0.873 \\
\hline$>60$ & $86(49.4 \%)$ & $148.87 \pm 79.04$ & & $2.73 \pm 1.37$ & \\
\hline \multicolumn{6}{|l|}{ Gender } \\
\hline Male & $122(70.1 \%)$ & $160.92 \pm 91.50$ & 0.387 & $3.09 \pm 1.64$ & $0.001 *$ \\
\hline Female & $52(29.9 \%)$ & $148.26 \pm 79.22$ & & $2.24 \pm 1.27$ & \\
\hline \multicolumn{6}{|l|}{ Clinical symptoms } \\
\hline No & $40(23.0 \%)$ & $127.44 \pm 47.63$ & $0.117^{\#}$ & $2.21 \pm 0.88$ & $0.014^{* \#}$ \\
\hline Cough or expectoration & $75(43.1 \%)$ & $154.56 \pm 73.66$ & & $2.74 \pm 1.35$ & \\
\hline Haemoptysis & $28(16.1)$ & $168.30 \pm 85.53$ & & $3.40 \pm 1.36$ & \\
\hline Chest pain & $19(10.9)$ & $173.73 \pm 85.58$ & & $2.95 \pm 1.84$ & \\
\hline Others & $12(6.9 \%)$ & $149.01 \pm 98.37$ & & $2.76 \pm 1.98$ & \\
\hline \multicolumn{6}{|l|}{ Smoking history } \\
\hline Never & $64(36.8 \%)$ & $157.99 \pm 79.69$ & 0.441 & $2.39 \pm 1.22$ & $0.010^{*}$ \\
\hline Smoker & $110(63.2 \%)$ & $148.90 \pm 71.90$ & & $2.96 \pm 1.48$ & \\
\hline \multicolumn{6}{|l|}{ COPD history } \\
\hline YES & $35(20.1 \%)$ & $156.09 \pm 93.48$ & 0.939 & $3.10 \pm 1.65$ & 0.267 \\
\hline $\mathrm{NO}$ & $139(79.9 \%)$ & $157.37 \pm 86.85$ & & $2.76 \pm 1.56$ & \\
\hline \multicolumn{6}{|l|}{ Type of resection } \\
\hline Sublobectomy & $11(6.3 \%)$ & $140.52 \pm 114.86$ & $0.872^{\#}$ & $2.68 \pm 2.35$ & $0.942^{\#}$ \\
\hline Lobectomy & $128(73.6 \%)$ & $150.94 \pm 67.87$ & & $2.72 \pm 1.26$ & \\
\hline Biolectomy & $28(16.1 \%)$ & $153.98 \pm 79.80$ & & $2.90 \pm 1.74$ & \\
\hline Peneumonectomy & $7(4.0 \%)$ & $179.04 \pm 103.00$ & & $2.81 \pm 1.01$ & \\
\hline \multicolumn{6}{|l|}{ Sleeve lobectomy } \\
\hline YES & $41(23.6 \%)$ & $146.88 \pm 54.55$ & 0.600 & $2.90 \pm 1.44$ & 0.454 \\
\hline $\mathrm{NO}$ & $133(76.4 \%)$ & $153.90 \pm 80.07$ & & $2.71 \pm 1.41$ & \\
\hline \multicolumn{6}{|l|}{ Tumor location } \\
\hline Left & $70(40.2 \%)$ & $157.98 \pm 78.53$ & 0.408 & $2.89 \pm 1.30$ & 0.278 \\
\hline Right & $104(59.8 \%)$ & $148.39 \pm 72.24$ & & $2.66 \pm 1.47$ & \\
\hline \multicolumn{6}{|l|}{ Pathological type } \\
\hline $\mathrm{AC}$ & $64(36.8 \%)$ & $137.51 \pm 64.82$ & $0.006^{* \#}$ & $2.48 \pm 1.31$ & $0.012^{* \#}$ \\
\hline SCC & $96(55.2 \%)$ & $165.21 \pm 74.96$ & & $3.15 \pm 1.48$ & \\
\hline Others & $14(8.0 \%)$ & $193.98 \pm 110.14$ & & $2.75 \pm 1.42$ & \\
\hline \multicolumn{6}{|l|}{ Pathological stage } \\
\hline $\mathrm{I}$ & $29(16.7 \%)$ & $135.55 \pm 42.24$ & $0.280^{\#}$ & $2.44 \pm 1.057$ & $0.380^{\#}$ \\
\hline II & $34(19.5 \%)$ & $172.87 \pm 92.20$ & & $3.06 \pm 1.38$ & \\
\hline III & $88(50.6 \%)$ & $152.15 \pm 86.98$ & & $2.77 \pm 1.64$ & \\
\hline IV & $23(13.2 \%)$ & $169.58 \pm 98.34$ & & $3.05 \pm 1.93$ & \\
\hline
\end{tabular}

$* \mathrm{P}<0.05$ is significant. Data are presented as $\mathrm{n}(\%)$ or mean \pm standard differences.

Data are compared by student t test or \# by one-way ANOVA (Analysis of Variance)

AC: adenocarcinoma; SCC: squamous carcinoma.

for PLR and 2.9 for NLR. Besides, the area under the curve (AUC) for PLR and NLR were $0.628(P=0.037$, $95 \% \mathrm{CI}=0.493-0.763)$ and $0.648(P=0.016,95 \% \mathrm{CI}=$ 0.531-0.766 ), separately (Figure 1). Based on the cut-off value, a total of 71 patients $(40.8 \%)$ were detected with high preoperative PLR ( $>$ 148.6, Table 2 ) and in the same way 69 patients $(39.7 \%)$ had high preoperative NLR ( > 2.9, Table 2). 
Table 3: The relationship between PLR, NLR and postoperative complications

\begin{tabular}{|l|l|l|l|l|l|l|}
\hline \multirow{2}{*}{} & PLR & \multicolumn{2}{l|}{ NLR } & \\
\cline { 2 - 7 } & $\leq \mathbf{1 4 8 . 6}$ & $\mathbf{1 4 8 . 6}$ & $\boldsymbol{P}$ value & $\leq \mathbf{2 . 9}$ & $\mathbf{2 . 9}$ & $\boldsymbol{P}$ value \\
\hline Number & $103(59.2 \%)$ & $71(40.8 \%)$ & - & $105(60.3 \%)$ & $69(39.7 \%)$ & - \\
\hline Pulmonary complications & & & & & & \\
\hline Pneumonia & $22(21.4 \%)$ & $29(40.8 \%)$ & $0.006^{*}$ & $25(23.8 \%)$ & $26(37.7 \%)$ & $0.049^{*}$ \\
\hline Bronchopleural fistula & $2(1.9 \%)$ & $2(2.8 \%)$ & $0.705^{\#}$ & $3(2.9 \%)$ & $1(1.4 \%)$ & $0.929^{\#}$ \\
\hline Respiratory failure & $12(11.7 \%)$ & $8(11.3 \%)$ & 0.938 & $12(11.4 \%)$ & $8(11.6 \%)$ & 0.973 \\
\hline ARDS/ALI & $21(20.4 \%)$ & $17(23.9 \%)$ & 0.577 & $20(19.0 \%)$ & $18(26.1 \%)$ & $0.027^{*}$ \\
\hline Atelectasis & $13(12.6 \%)$ & $16(22.5 \%)$ & 0.085 & $8(7.6 \%)$ & $21(30.4 \%)$ & $<0.001^{*}$ \\
\hline Any & $30(29.1 \%)$ & $35(49.3 \%)$ & $0.007^{*}$ & $30(28.6 \%)$ & $35(50.7 \%)$ & $0.003^{*}$ \\
\hline Extra-Pulmonary complications & & & & & & \\
\hline Arrhythmia & $14(13.6 \%)$ & $11(15.5 \%)$ & 0.725 & $11(10.05 \%)$ & $14(20.3 \%)$ & 0.071 \\
\hline Cardiac failure & $4(3.9 \%)$ & $4(5.6 \%)$ & $0.717^{\#}$ & $6(5.7 \%)$ & $2(2.9 \%)$ & $0.619^{\#}$ \\
\hline Poor wound healing & $7(6.8 \%)$ & $13(18.3 \%)$ & $0.013^{*}$ & $9(8.6 \%)$ & $11(15.9 \%)$ & 0.136 \\
\hline Prolonged airleak & $16(15.5 \%)$ & $17(23.9 \%)$ & 0.164 & $17(16.2 \%)$ & $16(23.2 \%)$ & 0.249 \\
\hline Chest drainage(ml) & $820 \pm 688$ & $860 \pm 597$ & 0.708 & $792 \pm 672$ & $901 \pm 623$ & 0.315 \\
\hline Hospital mortality & $2(1.9 \%)$ & $2(2.8 \%)$ & $0.540^{\#}$ & $3(2.9 \%)$ & $1(1.4 \%)$ & $0.480^{\#}$ \\
\hline Postoperative hospital stay (days) $)$ & $11.45 \pm 3.43$ & $13.47 \pm 4.56$ & $0.002^{* \&}$ & $11.71 \pm 3.73$ & $13.13 \pm 4.36$ & $0.032^{* \&}$ \\
\hline
\end{tabular}

$* P<0.05$ is significant

Data are presented as $\mathrm{n}(\%)$ or mean \pm standard differences.

Data are compared by $\chi 2$ test or \# by Fisher's exact test; $\&$ By student $t$ test

ARDS: Acute Respiratory Distress Syndrome; ALI: Acute Lung Injury

Table 4: univariate Cox regression analysis for PLR and NLR of RFS and OS

\begin{tabular}{|l|l|l|l|l|}
\hline & \multicolumn{3}{|l|}{ Overall survival } & \multicolumn{2}{l|}{ Progression-free survival } \\
\cline { 2 - 5 } & HR(95\%CI) & $\boldsymbol{P}$ value & HR(95\%CI) & $\boldsymbol{P}$ value \\
\hline Age $(\leq 60,>60)$ & $0.96(0.40-2.30)$ & 0.927 & $1.27(0.69-2.32)$ & 0.444 \\
\hline Gender (Male/ Female) & $2.26(0.93-5.50)$ & 0.084 & $1.41(0.73-2.71)$ & 0.310 \\
\hline Smoke history (yes, no) & $1.32(0.58-3.05)$ & 0.523 & $1.06(0.59-1.93)$ & 0.841 \\
\hline COPD & $1.31(0.52-3.29)$ & 0.561 & $1.41(0.73-2.72)$ & 0.304 \\
\hline Pathological stage & & & & \\
\hline (I/II)/ (III/IV) & $3.36(1.15-9.79)$ & $0.026^{*}$ & $2.20(1.12-4.32)$ & $0.022^{*}$ \\
\hline Pathological type & & & & \\
\hline AC & 1 & & 1 & 0.753 \\
\hline SCC & $1.11(0.47-2.65)$ & 0.805 & $0.91(0.49-1.67)$ & 0.786 \\
\hline Others & $2.85(0.40-3.32)$ & 0.071 & $1.16(0.40-3.33)$ & $0.017^{*}$ \\
\hline PLR & $1.06(1.02-1.10)$ & $0.002^{*}$ & $1.04(1.01-1.07)$ & \\
\hline NLR & $1.37(1.08-1.73)$ & $0.010^{*}$ & $1.14(0.95-1.38)$ & 0.162 \\
\hline
\end{tabular}

$* P<0.05$ is significant

HR: hazard rate; $95 \% \mathrm{CI}$ : 95\% confidence interval;

\section{Association between the PLR or NLR and postoperative clinical outcomes}

The postoperative clinical outcomes were compared between patients according to their PLR or NLR status through $\chi^{2}$ test or Fisher's exact test and the results were showed in Table 3. High PLR $(>148.6)$ was significantly correlated with high rate of pneumonia $(P=$ $0.006)$, pulmonary complications $(P=0.007)$, length of postoperative hospital stay $(P=0.002)$ and poor wound healing $(P=0.013)$. The High level of PLR did not correlate with respiratory failure $(P=0.938)$, ARDS $(P=$ $0.577)$ or atelectasis $(P=0.085)$. When it comes to NLR, high $\operatorname{NLR}(>2.9)$ significantly associate with high rate of pneumonia $(P=0.049)$; pulmonary complications $(P=$ $0.003)$, length of postoperative hospital stay $(P=0.032)$ and postoperative atelectasis $(P<0.001$, Table 3$)$. High NLR had no association with respiratory failure $(P=$ 0.973 ) and extra-pulmonary complications (Table 3 ). 


\section{Association of the PLR and NLR with survival}

The median follow-up duration was 11 months (IOR, 7-16). Patients with high PLR had a worse oneyear OS than those with low PLR $(90.3 \%$ vs. $77.5 \%, P$ $=0.034$ ) (Figure 2C). Different from PLR, no significant difference was investigated between groups concerning NLR (90.5\% vs. $76.8 \%, P=0.072)$. However, a potential trend between high NLR and a worse OS remained to be seen from the ROC curve (Figure 2D). There were no significantly difference observed in relapse-free survival between different level of PLR or NLR $(P=0.401, P=$ 0.242 , Figure 2A, 2B).
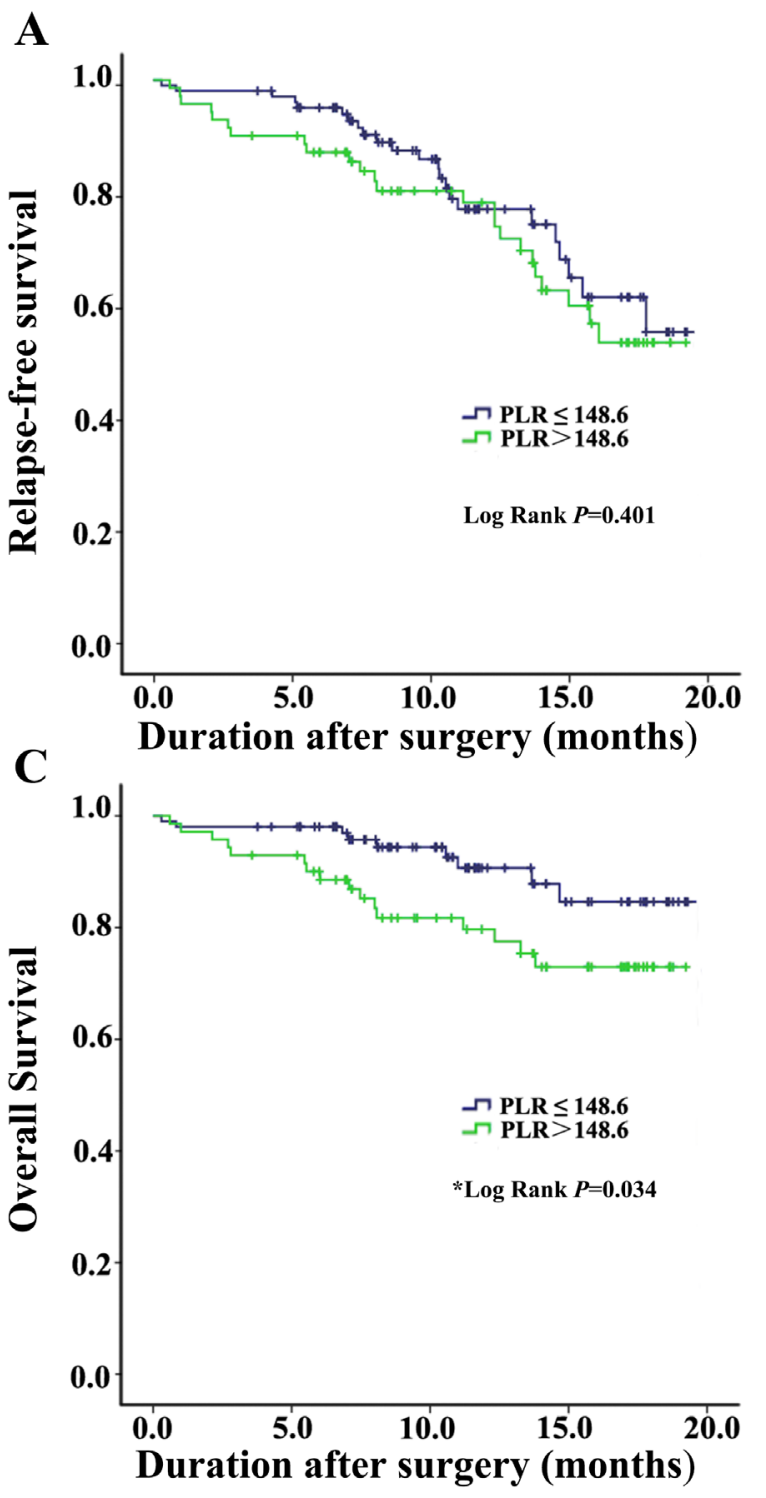

\section{Cox regression analysis}

The results of univariate and multivariate analyses for survival were shown in Table 4 and Table 5. On univariate analysis, high pathological stage (hazard ratio (HR) 3.36 ; 95\% CI 1.15-9.79, $P=0.026$, Table 4), PLR (HR:1.06 95\% CI: 1.02-1.10, $P=0.002$, Table 4) and NLR (HR:1.37 95\% CI 1.08-1.73, $P<0.010$, Table 4) were significant prognostic factors for poor OS. Meanwhile high stage (III/IV) of NSCLC (HR:2.20; 95\% CI 1.124.32, $P<0.022$ ) and PLR (HR:1.04; 95\% CI 1.01-1.07, $P<0.017$, Table 4 ) were associated with poor RFS. No significance difference was observed between preoperative
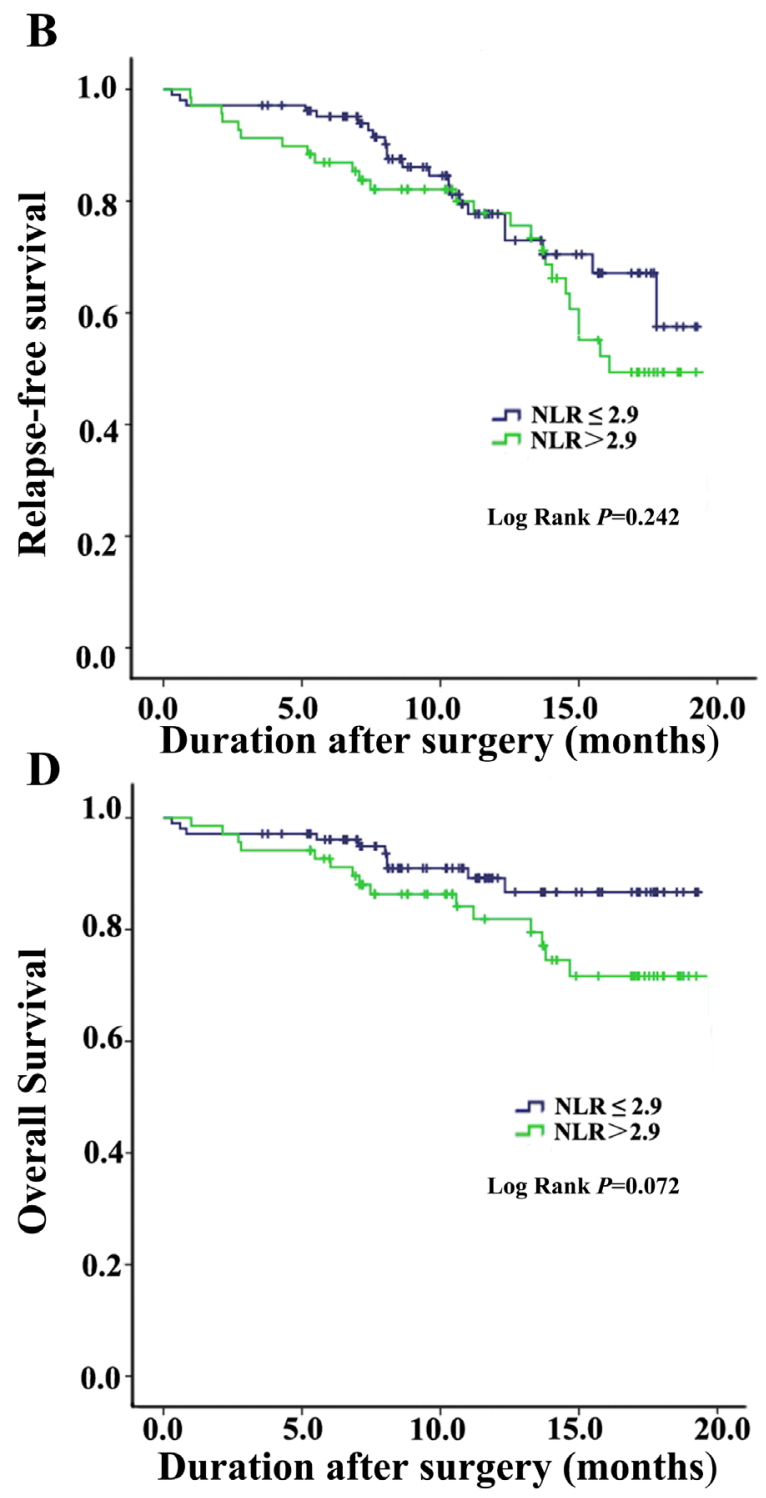

Figure 2: Kaplan-Meier curves estimates for the effect of pretreatment PLR, PLR on RFS and OS of NSCLC patients. A. Relapse-free survival curves at one year (Kaplan-Meier analysis) for NSCLC patients with PLR $\leq 148.6$ or $>148.6$. B. Relapse-free survival curves at one year (Kaplan-Meier analysis) for NSCLC patients with NLR $\leq 2.9$ or $>2.9$. C. Overall survival curves at one year (Kaplan-Meier analysis) for NSCLC patients with PLR $\leq 148.6$ or $>148.6$. D. Overall survival curves at one year (Kaplan-Meier analysis) for NSCLC patients with NLR $\leq 2.9$ or $>2.9$. ${ }^{*} P<0.05$ is significant 
Table 5: multivariate Cox regression analysis for PLR and NLR of RFS and OS

\begin{tabular}{|l|l|l|l|l|}
\hline \multirow{2}{*}{} & Overall survival & \multicolumn{3}{l|}{ Progression-free survival } \\
\cline { 2 - 5 } & HR(95\%CI) & $\boldsymbol{P}$ value & HR(95\%CI) & P value \\
\hline Age $(\leq 60,>60)$ & $1.63(0.59-4.46)$ & 0.345 & $1.86(0.917-3.77)$ & 0.086 \\
\hline Gender (Male/ Female) & $2.68(0.63-11.52)$ & 0.185 & $1.70(0.67-4.35)$ & 0.266 \\
\hline Smoke history (yes, no) & $0.90(0.25-3.26)$ & 0.872 & $0.923(037-2.32)$ & 0.865 \\
\hline COPD & $1.23(0.45-3.52)$ & 0.689 & $1.24(0.59-2.62)$ & 0.566 \\
\hline Pathological stage & & & & \\
\hline (I/II)/ (III/IV) & $4.08(1.31-12.73)$ & $0.015^{*}$ & $2.9(1.39-6.07)$ & $0.005^{*}$ \\
\hline Pathological type & & & & \\
\hline AC & 1 & - & 1 & - \\
\hline SCC & $0.73(0.28-1.90)$ & 0.513 & $0.69(0.34-1.39)$ & 0.295 \\
\hline others & $0.95(0.23-3.85)$ & 0.938 & $0.51(0.15-1.72)$ & 0.275 \\
\hline PLR & $1.01(1.00-1.01)$ & 0.103 & $1.06(1.01-1.11)$ & $0.023^{*}$ \\
\hline NLR & $1.04(0.73-1.49)$ & 0.819 & $0.96(0.74-1.25)$ & 0.761 \\
\hline
\end{tabular}

$* P<0.05$ is significant

HR: hazard rate; 95\% CI: 95\% confidence interval;

NLR and RFS ( $P=0.162$, Table 4). Multivariate analysis identified pathological stage (HR: 4.08 ; $95 \%$ CI 1.31 $12.73, P=0.015)$ as an independent poor prognostic factor for OS and PLR (HR 1.06); 95\% CI 1.01-1.11; $P=0.023$ ) as an independent poor prognostic factor for RFS (Table 5). There was no significant association between PLR (P $=0.103)$ or NLR $(P=0.819)$ and NSCLC patients' oneyear OS.

\section{DISCUSSION}

In this prospective observation study, the prognostic role of preoperative PLR and NLR in NSCLC patients who underwent radical lung resection were assessed. The main finding of this study is that high preoperative PLR or NLR level indicates high risk of postoperative complications in those patients. Besides, neither PLR nor NLR correlate with worse RFS and only high preoperative PLR has a significant association with worse one-year OS.

The preoperative PLR and NLR are simply, inexpensively and widely available markers to reflect systemic inflammation status [10,17, 18]. Several recent studies have demonstrated that preoperative inflammation state is associated with a worse postoperative outcome after surgery [19-21]. Our study showed that both preoperative PLR and NLR have a positive correlation with the PPCs particularly pneumonia and atelectasis in NSCLC patients undergoing radical surgery. As immune cells, platelets can initiate and accelerate many vascular inflammatory conditions $[22,23]$. It may contribute to the ischemia-reperfusion injury induced by one lung ventilation and surgical injury. Previous study also has the similar result that preoperative thrombocytosis is associated with an increased risk of major postoperative complication [20]. Our study confirms these findings and further defines the nature of the association. We demonstrated that preoperative elevated PLR was independently associated with the development of postoperative pulmonary complication in patients with radical lung cancer surgery, but not associated with the wound healing condition.

NLR increases when neutrophil dependence inflammatory response was enhanced or lymphocyte meditated immune response was reduced, which may weaken antibacterial ability and toleration of surgery stress. Yasuhiko M. reported that NLR could independently predict the development of postoperative infectious complication and lower survival after gastrectomy[24]. Many previous researches study about prognostic value of pretreatment PLR or NLR of the NSCLC patients with chemotherapy[25, 26]. Few prospective research study about the preoperative PLR and NLR on postoperative complications of NSCLC patients. Our study reported 178 NSCLC patients with radical surgery and explore the prognostic value of both PLR and NLR. Besides, a shorter postoperative hospital stay also confirmed that NSCLC patients with low preoperative PLR or NLR had better postoperative recovery. Most patients of our study did not receive chemotherapy before surgery. Our study may provide good predictive indices for NSCLC patients without chemotherapy.

The secondary objective of our study is to evaluate the prognostic effect of PLR and NLR on OS and RFS. We observed that an increased preoperative PLR was significantly associated with a higher one-year overall survival of patients with NSCLC. The same trend was 
observed for NLR, although without statistical differences. The insufficiency of sample and short follow-up period may account for this result. A meta-analysis demonstrated PLR could act as a significant biomarker in the prognosis of various cancers included lung cancer [27]. Our findings are in agreement with these studies. The mechanisms behind these phenomena are not clear and it may involve many aspects. It is believed that platelets can influence multistep development of tumors [22]. A clinical research of 619 patients with epithelial ovarian cancer indicated that paraneoplastic thrombocytosis fuels tumor growth [28]. As for the relationship between high NLR and worse OS, neutrophils can favor tumor development and inhibit the activity of lymphocytes and other immune cells. Neutrophils are involved in tumor progression of nonsmall cell lung cancer [29]. The exact mechanisms behind the prognostic implications of an elevated NLR remain to be elucidated.

Moreover, we aim to provide a novel indicator for clinicians to efficiently estimate the optimal time course for surgical treatment of NSCLC patients. The peripheral blood count test is routinely performed in all patients. The preoperative PLR and NLR is easy to obtain and come with no extra costs for patients attempt to have a radical lung cancer surgery. It can be used for risk stratification of PPCs and postoperative long-term outcome of NSCLC patients in clinical trials and clinical practices.

Our study has several limitations. First, this study was performed in a single center, which might limit the generalizability of our observation to others. Second, the sample size of our study is small. Therefore, the risk of a type 2 error cannot be excluded. Third, our study included patients with all stage (I-IV) because of the uncertainty of the tumour stage before surgery. It increased the inhomogeneity of our study population. However, PLR and NLR were distributed balance among pathological stage. Last, the postoperative clinical outcomes were only followed up for one year. However, the trend of OS was still available.

In conclusion, preoperative PLR and NLR are independent prognostic factors of postoperative complications in NSCLC patients undergoing radical lung cancer surgery. Preoperative PLR also indicate their prognosis on cancer survival. Further investigation with larger scale is required to confirm the prognostic role of NLR and PLR in NSCLC patients undergoing radical lung cancer surgery.

\section{MATERIALS AND METHODS}

\section{Participants}

Between December 2014 and February 2016, patients with stage I-IV NSCLC in West China Hospital of Sichuan University who were going to receive lung cancer radical thoracotomy were enrolled. The inclusion criteria included: 1) age 30-80 years; 2) American Society of Anesthesiologists (ASA) classification $\leq$ III; 3) elective radical lung cancer thoracotomy. The exclusion criteria referred to: 1) infection or inflammatory conditions with clinical evidence; 2) recurrence tumor; 3) combined with other malignant tumor. The present study was approved by the Ethical Committee of West China Hospital of Sichuan University. All patients signed a written informed consent before entering the study.

\section{Perioperative management}

To avoid the influence of surgical techniques, all surgeries were performed by one same group of surgeons. As for one lung ventilation (OLV) strategy, the tidal volume was set at 6 to $8 \mathrm{~mL} / \mathrm{kg}$ and positive end-expiratory pressure (PEEP) was 6 to $8 \mathrm{cmH}_{2} \mathrm{O}$ under a volumecontrolled mode. Recruitment maneuver composed of a continuous positive airway pressure of $30 \mathrm{cmH}_{2} \mathrm{O}$ for 30 seconds was repeated every 30 minute before and after OLV to avoid atelectasis [30]. A relative strict fluid protocol was performed during the whole surgery [31]. After surgery, all patients were transferred to intension care unit (ICU) with tracheal tube and use the same analgesia pump for postoperative pain relief.

\section{Data collections and follow up}

The basic demographic data and clinical characteristics of all patients were collected. The postoperative clinical course of each patient was carefully observed and recorded daily till discharged or 30 days after surgery. Data of blood counts within 7 days before the surgery were recorded. The blood specimen were collected through veinpuncture carried out by experienced nurses[32]. The NLR was defined as the absolute neutrophil count divided by the absolute lymphocyte count and the PLR referred to the absolute platelets count divided by the absolute lymphocyte count. Moreover, a chest computed tomography (CT) scan need to be done before discharge.

The perioperative surveillance protocol was described previously. The postoperative pulmonary complications (PPCs) were defined as the presence of pneumonia, bronchopleural fistula, respiratory failure, ARDS/ALI or massive atelectasis [33]. Cardiovascular complications included arrhythmia and cardiac failure. The definition of prolonged air-leak was postoperative chest drainage tube placed more than 5 days. Hospital stay postoperative was the period from surgery day to discharge day or death day. Hospital mortality was limited within 30 days after surgery [34].

Follow-up was down every 3-month by telephone after surgery. The contents of follow-up included tumor 
progression, recurrence, metastasis and survival days. Progression was defined as tumor recurrence, metastasis or death. The tumor recurrence and metastasis was assessed by clinicians.

\section{Statistical methods}

Data collection was performed using Microsoft Office Excel and all statistical analysis was carried out with IBM SPSS Statistics for Windows, version 21.0 (IBM Corp, USA). Continuous data with a normal distribution was presented as mean \pm standard deviation and median (inter-quartile range, IOR) when variables were nonnormal distributions. Categorical data was described by frequency and percentage. Normality of data was tested through Kolmogorov-Smirnov one-sample test. Student's $t$ test or one-way ANOVA (Analysis of Variance) was used for continuous variables and Fisher's exact test or $\chi^{2}$ test was used for comparison of categorical data separately.

The ROC curve analysis was carried out to assess the prognostic ability of PLR, NLR. The optimal cut-off value for NLR and PLR were also available using the ROC curve. The optimal cutoff values were identified as the values that maximize the Youden index (sensitivity + specificity - 1) [35]. Survival curves were estimated with the Kaplan-Meier method. Association between the factors and prognosis were examined with univariate and multivariate Cox regression models. In all test, a $P$-values of $<0.05$ (two-tailed) was considered statistically significant.

\section{ACKNOWLEDGMENTS}

This study was funded by the grants form National Natural Science Foundation of China (30571785; 30972862); Sichuan Projects of China (2012FZ0121); and Techpool Research Fund. The authors would like to thank Dr. Haiping Wang for her help on data statistics.

\section{CONFLICTS OF INTEREST}

The authors declare that they have no potential conflict of interest relevant to this article.

\section{REFERENCES}

1. Torre LA, Bray F, Siegel RL, Ferlay J, Lortet-Tieulent J, Jemal A. Global cancer statistics, 2012. Cancer J Clin. 2015; 65: 87-108.

2. Fan H, Shao ZY, Xiao YY, Xie ZH, Chen W, Xie H, Qin GY, Zhao NQ. Incidence and survival of non-small cell lung cancer in Shanghai: a population-based cohort study. BMJ Open. 2015; 5: e009419.

3. Siegel R, DeSantis C, Virgo K, Stein K, Mariotto A, Smith T, Cooper D, Gansler T, Lerro C, Fedewa S, Lin C, Leach
C, Cannady RS, et al. Cancer treatment and survivorship statistics, 2012. Cancer J Clin. 2012; 62: 220-41.

4. Iseki Y, Shibutani M, Maeda K, Nagahara H, Ohtani H, Sugano K, Ikeya T, Muguruma K, Tanaka H, Toyokawa T, Sakurai K, Hirakawa K. Impact of the Preoperative Controlling Nutritional Status (CONUT) Score on the Survival after Curative Surgery for Colorectal Cancer. PLoS One. 2015; 10: e0132488.

5. Kobayashi N, Usui S, Kikuchi S, Goto Y, Sakai M, Onizuka M, Sato Y. Preoperative lymphocyte count is an independent prognostic factor in node-negative non-small cell lung cancer. Lung Cancer. 2012; 75: 223-7.

6. Hanahan D, Weinberg RA. Hallmarks of cancer: the next generation. Cell. 2011; 144: 646-74.

7. O’Leary DP, O‘Leary E, Foley N, Cotter TG, Wang JH, Redmond HP. Effects of surgery on the cancer stem cell niche. Eur J Surg Oncol. 2016; 42: 319-25.

8. Kos FT, Hocazade C, Kos M, Uncu D, Karakas E, Dogan M, Uncu HG, Ozdemir N, Zengin N. Assessment of Prognostic Value of "Neutrophil to Lymphocyte Ratio" and "Prognostic Nutritional Index" as a Sytemic Inflammatory Marker in Non-small Cell Lung Cancer. Asian Pac J Cancer Prev. 2015; 16: 3997-4002.

9. Ghanim B, Schweiger T, Jedamzik J, Glueck O, Glogner C, Lang G, Klepetko W, Hoetzenecker K. Elevated inflammatory parameters and inflammation scores are associated with poor prognosis in patients undergoing pulmonary metastasectomy for colorectal cancer. Interact Cardiovasc Thorac Surg. 2015; 21: 616-23.

10. Wu Y, Chen Y, Yang X, Chen L, Yang Y. Neutrophil-tolymphocyte ratio (NLR) and platelet-to-lymphocyte ratio (PLR) were associated with disease activity in patients with systemic lupus erythematosus. Int Immunopharmacol. 2016; 36: 94-9.

11. Koh CH, Bhoo-Pathy $\mathrm{N}, \mathrm{Ng} \mathrm{KL}$, Jabir RS, Tan GH, See MH, Jamaris S, Taib NA. Utility of pre-treatment neutrophil-lymphocyte ratio and platelet-lymphocyte ratio as prognostic factors in breast cancer. Br J Cancer. 2015; 113: $150-8$.

12. Yodying H, Matsuda A, Miyashita M, Matsumoto S, Sakurazawa N, Yamada M, Uchida E. Prognostic Significance of Neutrophil-to-Lymphocyte Ratio and Platelet-to-Lymphocyte Ratio in Oncologic Outcomes of Esophageal Cancer: A Systematic Review and Metaanalysis. Ann Surg Oncol. 2016; 23: 646-54.

13. Zhao QT, Yuan Z, Zhang H, Zhang XP, Wang HE, Wang ZK, Duan GC. Prognostic role of platelet to lymphocyte ratio in non-small cell lung cancers: A meta-analysis including 3,720 patients. Int J Cancer. 2016; 139: 164-70.

14. Seth R, Tai LH, Falls T, de Souza CT, Bell JC, Carrier M, Atkins H, Boushey R, Auer RA. Surgical stress promotes the development of cancer metastases by a coagulationdependent mechanism involving natural killer cells in a murine model. Ann Surg. 2013; 258: 158-68. 
15. St Hill CA, Krieser K, Farooqui M. Neutrophil interactions with sialyl Lewis $\mathrm{X}$ on human nonsmall cell lung carcinoma cells regulate invasive behavior. Cancer. 2011; 117: 4493505.

16. Yang P, Bamlet WR, Sun Z, Ebbert JO, Aubry MC, Krowka MJ, Taylor WR, Marks RS, Deschamps C, Swensen SJ, Wieben ED, Cunningham JM, Melton LJ, et al. Alpha1antitrypsin and neutrophil elastase imbalance and lung cancer risk. Chest. 2005; 128: 445-52.

17. Sanchez-Salcedo P, de-Torres JP, Martinez-Urbistondo D, Gonzalez-Gutierrez J, Berto J, Campo A, Alcaide AB, Zulueta JJ. The neutrophil to lymphocyte and platelet to lymphocyte ratios as biomarkers for lung cancer development. Lung Cancer. 2016; 97: 28-34.

18. Goh BK, Kam JH, Lee SY, Chan CY, Allen JC, Jeyaraj P, Cheow PC, Chow PK, Ooi LL, Chung AY. Significance of neutrophil-to-lymphocyte ratio, platelet-to-lymphocyte ratio and prognostic nutrition index as preoperative predictors of early mortality after liver resection for huge $(>/=10 \mathrm{~cm})$ hepatocellular carcinoma. J Surg Oncol. 2016; 113: 621-7.

19. Zhang T, Yang J, Ding C, Li Y, Gu L, Wei Y, Cao L, Gong J, Zhu W, Li N, Li J. Preoperative Intra-abdominal Sepsis, Not Penetrating Behavior Itself, Is Associated With Worse Postoperative Outcome After Bowel Resection for Crohn Disease: A Retrospective Cohort Study. Medicine (Baltimore). 2015; 94: e1987.

20. Barber EL, Boggess JF, Van Le L, Kim KH, Bae-Jump VL, Brewster WR, Soper JT, Gehrig PA. Association of Preoperative Thrombocytosis and Leukocytosis With Postoperative Morbidity and Mortality Among Patients With Ovarian Cancer. Obstet Gynecol. 2015; 126: 1191-7.

21. Becher RD, Hoth JJ, Miller PR, Meredith JW, Chang MC. Systemic inflammation worsens outcomes in emergency surgical patients. J Trauma Acute Care Surg. 2012; 72: 1140-9.

22. Franco AT, Corken A, Ware J. Platelets at the interface of thrombosis, inflammation, and cancer. 2015; 126: 582-8.

23. Morrell CN, Aggrey AA, Chapman LM, Modjeski KL. Emerging roles for platelets as immune and inflammatory cells. Blood. 2014; 123: 2759-67.

24. Mohri Y, Tanaka K, Toiyama Y, Ohi M, Yasuda H, Inoue Y, Kusunoki M. Impact of Preoperative Neutrophil to Lymphocyte Ratio and Postoperative Infectious Complications on Survival After Curative Gastrectomy for Gastric Cancer: A Single Institutional Cohort Study. Medicine (Baltimore). 2016; 95: e3125.

25. Chen Y, Chen K, Xiao X, Nie Y, Qu S, Gong C, Su F, Song E. Pretreatment neutrophil-to-lymphocyte ratio is correlated with response to neoadjuvant chemotherapy as an independent prognostic indicator in breast cancer patients: a retrospective study. BMC Cancer. 2016; 16: 320.
26. van Soest RJ, Templeton AJ, Vera-Badillo FE, Mercier F, Sonpavde G, Amir E, Tombal B, Rosenthal M, Eisenberger MA, Tannock IF, de Wit R. Neutrophil-to-lymphocyte ratio as a prognostic biomarker for men with metastatic castration-resistant prostate cancer receiving first-line chemotherapy: data from two randomized phase III trials. Ann Oncol. 2015; 26: 743-9.

27. Zhou X, Du Y, Huang Z, Xu J, Qiu T, Wang J, Wang T, Zhu W, Liu P. Prognostic value of PLR in various cancers: a meta-analysis. PLoS One. 2014; 9: e101119.

28. Stone RL, Nick AM, McNeish IA, Balkwill F, Han HD, Bottsford-Miller J, Rupairmoole R, Armaiz-Pena GN, Pecot CV, Coward J, Deavers MT, Vasquez HG, Urbauer D, et al. Paraneoplastic thrombocytosis in ovarian cancer. N Engl J Med. 2012; 366: 610-8.

29. Yamashita J, Ogawa M, Abe M, Hayashi N, Kurusu Y, Kawahara K, Shirakusa T. Tumor neutrophil elastase is closely associated with the direct extension of non-small cell lung cancer into the aorta. Chest. 1997; 111: 885-90.

30. Lohser J, Slinger P. Lung Injury After One-Lung Ventilation: A Review of the Pathophysiologic Mechanisms Affecting the Ventilated and the Collapsed Lung. Anesth Analg. 2015; 121: 302-18.

31. Mesa-Guzman M, Periklis P, Niwaz Z, Socci L, Raubenheimer H, Adams B, Gurung L, Uzzaman M, Lim E. Determining optimal fluid and air leak cut off values for chest drain management in general thoracic surgery. $\mathrm{J}$ Thorac Dis. 2015; 7: 2053-7.

32. Lowe G, Stike R, Pollack M, Bosley J, O'Brien P, Hake A, Landis G, Billings N, Gordon P, Manzella S, Stover T. Nursing blood specimen collection techniques and hemolysis rates in an emergency department: analysis of venipuncture versus intravenous catheter collection techniques. J Emerg Nurs. 2008; 34: 26-32.

33. Lunardi AC, Paisani DM, Marques da Silva CC, Cano DP, Tanaka C, Carvalho CR. Comparison of lung expansion techniques on thoracoabdominal mechanics and incidence of pulmonary complications after upper abdominal surgery: a randomized and controlled trial. Chest. 2015; 148: 100310.

34. Freeman RK, Dilts JR, Ascioti AJ, Dake M, Mahidhara RS. A comparison of length of stay, readmission rate, and facility reimbursement after lobectomy of the lung. Ann Thorac Surg. 2013; 96: 1740-5.

35. Lai CY, Tian L, Schisterman EF. Exact confidence interval estimation for the Youden index and its corresponding optimal cut-point. Comput Stat Data Anal. 2012; 56: 110314. 